Marco A. Bontá

\title{
Mi encuentro con los pintores del 13
}

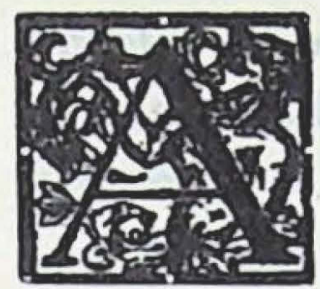

LLÁ por el año 1913, cuando vino a Chile el ilustre pintor español don Fernando Alvarez Sotomayor para hacerse cargo de la enseñanza artística en la Academia de Bellas Artes, mis aficiones pictóricas aún permanecían dormidas. Entonces a duras penas cursaba el segundo año de humanidades en el liceo del romántico barrio recoletano, ese barrio de señorío colonial y de frondosas encinas.

Era yo un malísimo estudiante que pasaba la mitad de las horas de clase dedicado a vagar por el cerro San Cristóbal, los campos del Guanaco, Conchalí o Vitacura. La atracción del paisaje y el amor a la naturaleza habían ejercido tal influencia en mis inclinaciones infantiles, que no me importaba un ápice sentirme apodado "cimarrero"; la vida de andariego contemplativo era uno de mis grandes placeres y mi orgullo de muchacho.

Nada podía impedir ni hacer remorder mi conciencia si abandonaba los estudios, mucho menos en primavera o verano, en esas épocas del año que las encinas juntas al liceo, de verdor luminoso, parecían, al sacudirlas la brisa levemente, hacernos señas a los estudiantes a través de los barrotes de las ventanas invitándonos a salir de las lúgubres salas de clase, que con su oscuridad y pobrísimo am- 
biente se tornaban tan dolorosas para los que no poseíamos ambiciones doctorales.

La canícula y la alegría del paísaje podían mucho más que los textos y que las sabias lecciones, ellas aguzaban el ingenio de los chiquillos para evadirse del viejo caserón, antiguo cuartel de policía; sobre todo el de aquellos que, como yo, no podían soportar tantas horas de encierro y mucho menos si la escapada tenía por objeto disfrutar de una tarde de libertad o de natación en uno de esos riachuelos del arrabal.

El deporte de la natación, en esos tiempos, era todavía desconocido como tal y apenas afición de unos cuantos muchachos corajudos que lo practicaban fuera de la ley, es decir, a escondidas, sin permiso de los apoderados, de los profesores, ni tampoco de los propietarios de sitios donde existía algún remanso adecuado para nadar, como eran el correntoso canal del Carmen, que corría a media falda del cerro San Cristóbal; más abajo, el estero del Molino Purísima, de agua con ofrecho $\mathrm{y}$, por último, el río Mapocho, de lecho pedregoso, turbio y helado.

Para llegar a estos lugares que, por otra parte, constituían los pocos rincones con agua en los cuales un modesto estudiante santiaguino podía practicar este deporte con cierta higiene, había que escalar tapias y esconderse, puesto que siempre existía el peligro de ser sorprendido por los rondines que con exagerado celo los vigilaban. Los bañistas furtivos y su presencia de terso cutis era considerada como un atentado contra la moral. Con frecuencia había que dejar precipitadamente el entrenamiento de cualquier manera, semidesnudos y a velocidades vertiginosas.

Aunque las expectativas de estas "piscinas" naturales no resultaban del todo halagüeñas, desde luego, por el contratiempo que significaba entrar "a la guerra", sin embargo, las preferíamos a las que existían por entonces en la capital: una en la avenida Providencia y otra en la calle San Diego. Cobraban módica suma por el baño, pero donde era corriente ver echarse al agua a los bañistas completamente enjabonados. 
Tampoco éramos muchos los aficionados que nos dábamos cita: unos pocos liceanos, uno que otro matoncillo de la Avenida Matta y algunos mozuelos de la "palomilla brava" del arrabal de Los Leones, que en las huídas demostraban ser los mejores compañeros, más aún, si llegaba la necesidad de defenderse a puño limpio de la agresividad de algún vigilante.

Una tarde de ésas, mientras el mismo grupo de todos los días disfrutaba de unas cuantas zambullidas y de algunas manotadas - todavía no se conocían los "estilos" natatorios de hoy- y el sol estival jugueteaba entre el follaje de las higueras, salpicando con manchas de oro el pozo hondo que habíamos formado con un taco de piedras junto al molino, la pandilla fué sorprendida por varios rondines, varilla en mano.

¡Qué desbandada! Unos chiquillos desnudos corrían cuesta arriba, otros hacia abajo y los que no alcanzaron a salir del agua, se sumergían largamente para esquivar la paliza que, desde la orilla, les propinaban sin mucha compasión. Por mi parte, algún milagro me favoreció, porque pude escapar de la confusión con los pantalones y unos libros en la mano en dirección del portón de Pío Nono.

Uno de los guardias me siguió casi pisándome los talones y sólo al llegar al terreno plano, a la calle Santa Filomena, pude tomarle distancia a aquel hombre que parecía tener las Botas de Siete Leguas. Las piedras y el asfalto caliente de la calle solitaria no lo sentí en mis pies, sino después que se me pasó el susto, cuando estaba oculto en el interior de una iglesia en construcción que encontré en mi camino y a donde había ido a refugiarme impulsado por el puro instinto de conservación.

En un rincón del templo, tras maderos y sacos de cal, terminé por vestirme. A la vez que mi respiración se serenaba poco a poco, me dí cuenta de que la iglesia estaba en las terminaciones y en su interior, desde unos andamios altísimos, un grupo de artistas daba los últimos toques a la decoración. Una extraña emoción comencé a experimentar al observar detenidamente el espectáculo que acababa de descubrir. Una sensación nueva me hizo recorrer las distintas na- 
ves y tanto me absorbió la contemplación de los hermosos motivos moriscos que pronto me olvidé de mi reciente aventura y de las aficiones deportivas.

En los andamios, los pintores silbaban y cantaban, haciendo vibrar la atmósfera interior del templo con el eco sonoro de sus voces baritonales y, desde el altar mayor al coro, se hacían bromas que eran seguidas de bulliciosas carcajadas.

-Pachín, ¿cómo fué eso de la falsificación de billetes? - preguntaba alguien desde arriba.

-Esas son cosas que me cuelga el "Ñato Pridas", para ver si consigue sacarme de mis casillas - respondió el que estaba más abajo, sentado en un tablón, retocando la voluta de un capitel.

-Tú no nos vas a contar cuentos ahora; Exequiel Plaza dice que tú lo quisiste hacer socio y le ofreciste un porcentaje.

Miré hacia arriba y vi al "ñato" que tenía una tremenda nariz, más parecida a un apagador de velas de sacristán, y apenas comprendí por qué lo llamarían así.

-El "Loro Gilbert" es el socio - gritó otro desde el extremo de la nave.

-A mí no van ustedes a llevarme en ese pértigo - respondió de inmediato una voz catarrienta, con escandalosas risotadas.

- A Ahí viene el "Cara de perro" - gritó el de la voluta, en el instante mismo que aparecía un cura por una de las puertas de la sacristía.

El sacerdote pareció oír la alusión, que seguramente iba dirigida a él, del mismo modo que la oí yo desde mi actitud distraída; porque de pronto vi que el cura se arremangaba las sotanas y se lanzaba corriendo hacia donde todavía quedaba retumbando la broma.

El ambiente alegre y festivo que amenizaba el trabajo de los pintores cambió de inmediato. El párroco, como un gato, comenzó a subir las escaleras tratando de alcanzar al osado que le había ofendido de ese modo; mientras tanto, el artista, por otro lado, por entre los palos, saltando de tablón en tablón, bajaba presintiendo que el ataque iba en serio. 
Una vez en las alturas el clérigo, como un ángel diabólico, rojo de ira, miraba con ojos fijos y brillantes a su ofensor que se escabullía en dirección a la calle. Los ánimos de todos parecieron electrizarse en un instante.

Pachín, al pasar junto a mí, miró para atrás y me dijo sonriendo, como haciéndome testigo de su observación:

-iMira, chiquillo, si no parece bulldog! Me voy porque el sotacura me va a morder...

Eché una mirada al religioso; descendía murmurando cosas que no entendí, salvo los nombres de Alfredo, Enrique Lobos, Pedro Luna, que los mezclaba con palabras extrañas, ininteligibles, como si hablara en latín. En verdad, no tenía aspecto muy santo.

La algarabía que alentó mi confianza para permanecer en el interior del templo en tan inusitadas relaciones artísticas, se había convertido en inmenso silencio. Sentí miedo y me marché.

De nuevo en la calle, vi al pintor que, con pasos ligeros, con sus hombros enjutos y un tanto inclinado de un lado, se alejaba presuroso, proyectando la sombra de su silueta menuda sobre la encalada pared de una de esas largas, angostas y laberínticas cités del barrio.

¡Famosos pasajes aquéllos! ésos que unían las calles de Santa Filomena y la de Andrés Bello, especie de guaridas de artistas, poetas, artesanos, matronas y doncellas; sobre todo el más pintoresco, "El conventillo de la Paloma" como lo llamaban cariñosamente los artistas.

No en vano había corrido esa tarde con tanta prisa; la carrera más veloz de mi vida, porque ella me llevó de una manera simbólica y violenta al conocimiento de un mundo nuevo, que mi conciencia de adolescente, hasta el momento, no había descubierto.

Todas las vicisitudes quedaban compensadas de sobra con este primer encuentro con pintores, que después habían de tener tanto 
significado para mí. Desde entonces no he perdido los pasos de aquel grupo, que era ni más ni menos la generación de 1913, los alumnos preferidos de Alvarez Sotomayor, los valores jóvenes que, a poco andar el tiempo, se convertirían en los guías espirituales de una de las etapas de mayor contenido de la pintura chilena. Hoy casi todos desaparecidos.

Ahora que trato de esbozar estas notas de nuestra vida artística y hago memoria del casual episodio de la iglesia de Santa Filomena, pienso que también yo he visto en mi viejo barrio de "ultramapocho" una pequeña Sixtina, en la cual no faltaba ni el cura, que al igual al Papa Julio II que subió los andamios para sancionar el tablón que le dejara caer Miguel Angel, aquí, éste, trepaba para castigar a Pachín por su realismo retratístico.

Artistas artesanos, de espíritu renacentista, eso era la generación de pintores del 13. 